\title{
Observações sobre a estrutura linguística da Cena: a língua de sinais emergente da Várzea Queimada (Piauí, Brasil)
}

\author{
Anderson Almeida-Silva ${ }^{1}$ \\ Departamento de Biologia, Universidade Federal do Delta do Parnaíba, Parnaíba, PI, Brasil \\ Andrew Ira Nevins ${ }^{2}$ \\ Departamento de Letras, Universidade Federal do Rio de Janeiro, Rio de Janeiro, RJ, Brasil
}

Resumo: Este texto apresenta uma descrição preliminar da estrutura linguística da Cena, uma língua de sinais emergente do interior do Piauí, falada/sinalizada por aproximadamente 30 pessoas. É classificada como uma língua de sinais compartilhada porque também é utilizada por pessoas ouvintes. A Cena é uma das línguas minoritárias do Brasil e é uma língua compartilhada por surdos e ouvintes da localidade Várzea Queimada. Descrevemos aspectos do léxico, fonologia, morfologia, sintaxe, e algumas questões de variação encontradas nessa língua, apontando para várias direções em pesquisas futuras. O texto é útil para aqueles interessados na temática de língua de sinais emergentes e a questão da evolução e tipologia das línguas.

Palavras-chave: Língua de sinais emergente; Descrição gramatical; Emergência linguística.

Title: Observations on the linguistic structure of Cena: an emergent sign language in Várzea Queimada (Piauí, Brasil)

Abstract: This paper presents a preliminary description of the linguistic structure of Cena, an emerging sign language in the interior of Piauí spoken/signed by approximately 30 people. It may be classified as a sign language that is also shared and used with hearing people. Cena is of one of the minority languages found in Brazil and it is a language shared between the deaf and hearing community of Várzea Queimada. We describe aspects of the lexicon, phonology, morphology, syntax, and aspects of variation that are found in this language, along with pointing out directions for future research. This article may be useful to those interested in the topic of emerging sign languages within the context of evolutionary and typological issues of language.

Keywords: Emerging sign languages; Grammatical description; Linguistic emergence.

\section{Introdução}

Este artigo tem por objetivo efetuar uma descrição linguística preliminar da Cena, uma língua de sinais emergente (LSE) utilizada na comunidade de Várzea Queimada, povoado da cidade de Jaicós, no sudoeste do Piauí. A Cena se encaixa no rol das línguas

\footnotetext{
${ }^{1}$ Doutor em Linguística (UNICAMP), Professor adjunto na UFDPAR. Orcid: https://orcid.org/0000-0003-43694885. E-mail: andersonalmeida@ufpi.edu.br.

${ }^{2}$ Doutor em Linguística (MIT), Professor titular na UFRJ. Orcid: https://orcid.org/0000-0001-5318-5596. E-mail: andrewnevins@letras.ufrj.br.
} 
minoritárias, pois é utilizada com diferentes graus de frequência por uma comunidade de 33 surdos $^{3}$, dentro de um universo de mais ou menos 900 habitantes. A língua que começou a se desenvolver na década de 50 pode estar agora ameaçada pela ausência de novas gerações falantes de Cena, pois não há registro de crianças surdas nascendo na comunidade, e por ser uma língua em risco de extinção, sua análise e descrição são urgentes (BRAITHWAITE, 2019).

A língua surgiu na década de 50 com o nascimento da primeira surda da comunidade em 1949, que hoje tem 71 anos de idade. Ela não é mais usuária da Cena da Várzea Queimada, pois há algumas décadas ela se mudou para uma outra localidade chamada Peixe, e daí não acompanhou a evolução dos sinais, mas se comunica com os surdos da Várzea com facilidade. Logo após o nascimento desta primeira surda na comunidade, outra família da Várzea teve 6 filhos surdos de um total de 14. A mais velha dentre os 6 surdos tem 62 anos de idade, ou seja, estes surdos tiveram sua infância juntos à primeira surda nascida na comunidade e, possivelmente, destas conversas entre os primeiros 7 surdos da região foise criando a comunicação manual apelidada até hoje pela comunidade ouvinte de 'Cena', ou 'fazer cena' quando querem dizer 'sinalizar com as mãos'. Após o nascimento destes primeiros surdos, já estamos agora na terceira geração de surdos na Várzea Queimada, ou seja, a Cena já tem mais ou menos três gerações na comunidade e os surdos mais novos têm entre 13 e 15 anos de idade. Não há mais registros de novos surdos na comunidade nos últimos anos.

\section{O que são e por que investigar as LSEs?}

A experiência linguística não deixa fósseis arqueológicos, e criamos hipóteses sobre isso somente quando mais ou menos a humanidade teria começado a falar (ou sinalizar). Não há evidências concretas que resolvam de uma vez por todas o debate sobre quando e como a capacidade para a linguagem teria emergido em nossa espécie.

Conseguimos rastrear com árvores filogenéticas os troncos de línguas antigas e modernas com base em suas características tipológicas comuns, mas nunca se pôde descrever a protolíngua que seria a língua-mãe de todas as línguas do mundo (se apenas surgiu uma vez). Até a presente data, esta protolíngua tem somente uma realidade hipotética, já que no geral, as línguas orais (LOs) se desenvolvem a partir de um curso evolutivo ou da mistura de duas ou mais línguas (como são os casos dos pidgins e dos crioulos) (COUTO, 1996). Porém, não se tem registro de novas línguas orais surgindo 'do nada', pois não se atestam populações tão isoladas nas quais os genitores não possuam uma língua, e esta, então, seria criada a partir das gerações seguintes.

Interessante e diferentemente do que se atesta nas línguas orais nos casos dos pidgins e dos crioulos, atestamos várias línguas de sinais (LSs) emergindo na atualidade, sem

\footnotetext{
${ }^{3}$ Censo realizado por nosso grupo de pesquisa em dezembro de 2019. 24 surdos têm residência fixa na Várzea, enquanto 9 surdos moram em localidades próximas à comunidade ou visitam seus familiares com relativa frequência, mas não residem na Várzea.
} 
a clara influência de uma outra língua, ou seja, sem o suporte de um outro modelo linguístico que sirva de substrato (MEIR et al. 2010), são esses sistemas de comunicação manual que denominam-se línguas de sinais emergentes. As LSEs surgem em contextos nos quais uma comunidade surda se encontra, por algum motivo, isolada do input de uma outra língua de sinais estável, em um local em que se identifica uma alta incidência de surdez hereditária. A porcentagem de surdos em relação aos ouvintes nestas comunidades chega a ser 40 vezes maior do que a média de outras comunidades (ibidem).

Sandler et al. (2014) definem as línguas de sinais emergentes como o fruto de um 'experimento proibido', pois em nenhuma hipótese algum comitê de ética consideraria aprovar uma pesquisa que se propusesse a testar se seres humanos isolados por duas gerações ou mais, na ausência de um input linguístico, poderiam desenvolver uma nova língua. Esse experimento incorreria em crime de negligência para aquisição de uma língua materna, violando os direitos humanos universais, o que já conhecemos ter efeitos arrasadores ao sistema linguístico e cognitivo (LENNEBERG, 1967; FROMKIN et al., 1974; JOHNSON; NEWPORT, 1989; MORGAN, 2014).

Por essa breve exposição, fica evidente que as línguas de sinais emergentes são um campo relevante para a investigação científica, pois podem contribuir para o entendimento de como as línguas podem ter se originado, e ainda como emergem certas estruturas linguísticas essenciais para o funcionamento da gramática, entendida aqui nos moldes da teoria gerativa (CHOMSKY, 1965 e publicações subsequentes). Portanto, localidades como a Várzea Queimada, em que uma comunidade surda se encontra bastante isolada principalmente por questões geográficas durante quase 70 anos, e na qual se atesta o surgimento de um código linguístico distinto de qualquer outro existente, são verdadeiros laboratórios a céu aberto.

As LSEs não são o único caso de que se tem conhecimento em que populações com algum tipo de impedimento auditivo desenvolvem uma língua, temos também os casos dos sinais caseiros e das línguas de sinais alternativas (secondary). Veremos cada um deles a seguir.

De Vos e Pfau (2015) explicam que crianças surdas filhas de pais ouvintes que não sabem LSs tendem a criar um código linguístico denominado de sinais caseiros (homesigns), que são geralmente utilizados no seio de uma família, portanto, não é um código compartilhado com outros indivíduos, uma língua. Goldin-Meadow e Mylander (1990) mostraram, a partir de filmagens longitudinais com crianças surdas utilizando sinais caseiros, que elas têm a capacidade inata de superar o uso estritamente paralinguístico (adjunto) dos gestos dos pais e imprimir regularidade e sistematicidade no uso dos gestos, evidenciando nos sinais caseiros propriedades básicas de uma língua natural como a linearidade e a composicionalidade. Ou seja, crianças com ou sem um guia (um modelo linguístico) poderiam, a partir de uma capacidade inata, estabelecer regularidades ao input semilinguístico recebido (SINGLETON; NEWPORT, 2004) fazendo emergir um novo sistema 
linguístico ${ }^{4}$.

Do mesmo modo, há vários relatos de comunidades ouvintes em que se tenha algum tipo de impedimento ou proibição para fazer o uso da fala oral, criando sistemas de comunicação sinalizados. Essas 'línguas de sinais' são denominadas na literatura como LSs alternativas ou secundárias, uma vez que não são utilizadas primariamente por surdos, mas o seu uso frequente acaba por assemelhar-se aos casos de emergência linguística, uma vez que muitos desses sistemas, dada a alta frequência de uso, já apresentavam traços de uma gramática rudimentar. São exemplos dessas línguas de sinais alternativas a língua de sinais dos povos indígenas das planícies americanas - criada a partir do contato de falantes de diferentes línguas orais de diferentes etnias (TOMKINS, 1931 [1969]), as línguas de sinais dos trabalhadores de serralherias - criadas em ambientes de extremo ruído (MEISSNER; PHILPOTT, 1975), sinais utilizados por comunidades aborígenes em rituais de iniciação dos meninos e durante o luto de viúvas - períodos nos quais não se é permitido falar oralmente (KENDON, 1984), sinais criados por monges cistercienses, trapistas e cluníacos - em contextos de votos de silêncio (BARAKAT, 1975) - e os sinais utilizados pelos grupos étnicos Khoisan para coordenar estratégias de caça e não afugentar os animais com os ruídos (HINDLEY, 2014).

Embora os gestos caseiros e as LSs alternativas sejam formas nas quais se evidencia algum tipo de emergência linguística, eles sozinhos não criam LSs naturais, pois surgem em contextos individuais ou de grupos pequenos que não envolvem diretamente os surdos. Como vemos no esquema abaixo, os gestos caseiros e as LSs secundárias não são tão complexos estruturalmente como uma LS natural, embora possam contribuir de algum modo para a formação delas.

Dentro dos dados das 'línguas de sinais naturais', identificamos diferentes tipos de comunidades surdas, e estas comunidades compõem o que Zeshan (2006) denomina de o 'mosaico dos dados das $L S s^{\prime}$ no mundo. Para fins desta exposição, vamos abrir mão de dicotomias tais como: LSs urbanas vs. LSs rurais ou LSs ocidentais vs. LSs orientais, sem negar a importância desses contextos na classificação dos dados das LSs no mundo. No entanto, nos interessa aqui abordar o contraste entre as LSs emergentes vs. LSs estáveis, independentemente do contexto de emergência ter sido em uma localidade urbana, rural, ocidental ou oriental, já que sabemos também que os próprios padrões geográficos não são equiparáveis se considerarmos países e continentes com dimensões geográficas e padrões de desenvolvimento econômico distintos. Vale a pena frisar aqui, no entanto, que a distinção 'emergente vs. estável' seria talvez mais bem classificada em termos de 'LSs locais vs. LSs nacionais', já que os segundos grupos gozam de algum tipo de apoio institucional, o que forçaria uma padronização da língua de cima para baixo.

Na literatura, não há consistência no uso do termo que designa as LSEs que podem aparecer sob o rótulo de línguas de sinais de vila, rurais, compartilhadas ou emergentes. Neste texto, utilizaremos o rótulo língua de sinais emergente - LSE. No quadro abaixo compilamos todas as LSEs com publicações conhecidas na literatura. $\mathrm{O}$ quadro agrega dados

\footnotetext{
${ }^{4}$ Para uma proposta de expansão no conceito de sinais caseiros, utilizados em áreas rurais, cf. Reed (2019).
} 
que já estavam disponíveis De Vos e Pfau (2015, p. 268), Silva e Quadros (2019, p. 2211822121) e Le Guen (2019), atualizando-a com novos dados. Para as referências completas dos dados que aparecem neste quadro, o leitor pode consultar a fonte original do trabalho referenciado no eixo vertical.

Quadro 1: Listagem das Línguas de Sinais Emergentes no Mundo

\begin{tabular}{|c|c|c|c|}
\hline Língua de sinais emergente & Localidade & Referências & \\
\hline LS Adamorobe & Gana & $\begin{array}{l}\text { David et al., 1971; Nyst 2007a, } \\
\text { 2007b, } 2008\end{array}$ & \multirow{13}{*}{ 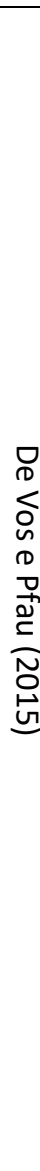 } \\
\hline LS Al-Sayid Beduína & Israel & $\begin{array}{l}\text { Aronoff et al., 2005, 2008; Kisch } \\
2008,2012 ; \text { Sandler et al., 2005, } \\
2011\end{array}$ & \\
\hline LS de Judeus argelinos & $\begin{array}{l}\text { Originalmente, Argélica, } \\
\text { agora França e Israel }\end{array}$ & Lanesman e Meir, 2012 & \\
\hline LS Alipur & Índia & Panda, 2012; Zeshan et al., 2013 & \\
\hline LS Ban Khor & Tailândia & $\begin{array}{l}\text { Woodward, 2003; Nonaka, 2004, } \\
\text { 2009, 2011, } 2012\end{array}$ & \\
\hline LS Maia Yucatec & México & $\begin{array}{l}\text { Shuman, 1980; Johnson 1991; Fox } \\
\text { Tree, 2009, Escobedo Delgado, } \\
\text { 2012; Le Guen, 2012; Zeshan et al., } \\
2013\end{array}$ & \\
\hline LS Kata Kolok & Bali, Indonésia & $\begin{array}{l}\text { Branson et al., 1996, 1999; Marsaja } \\
\text { 2008; Perniss e Zeshan, 2008; de } \\
\text { Vos 2011, 2012a, 2012b }\end{array}$ & \\
\hline LS Koinchri Sain & Jamaica & Dolman, 1986; Adone et al., 2012 & \\
\hline LS Inuit & Nunavut, Canadá & $\begin{array}{l}\text { MacDougall, 2001; Schuit et al., } \\
\text { 2011; Schuit, 2012, } 2013\end{array}$ & \\
\hline LS Mardin & Turquia & Dikyuva, 2012; Zeshan et al., 2013 & \\
\hline LS de Martha's Vineyard & Nordeste dos Estados Unidos & Groce, 1985 & \\
\hline LS das Ilhas de Providência & Colômbia & $\begin{array}{l}\text { Washabaugh et al., 1978; } \\
\text { Washabaugh 1979, 1980, 1986; } \\
\text { Woodward, 1978, } 1982\end{array}$ & \\
\hline LS Ka'apor & Brasil & $\begin{array}{l}\text { Kakumasu 1968; Brito, 1983; } \\
\text { Godoy, } 2020\end{array}$ & \\
\hline LS de Sateré-mawé & Parintins - Manaus, Brasil & Azevedo, 2015 & \multirow{13}{*}{ 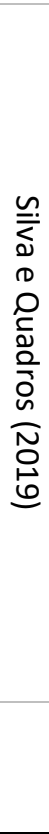 } \\
\hline LS Kaingang & Xanxerê - Santa Catarina, Brasil & Giroletti, 2008 & \\
\hline LS Terena & Mato Grosso do Sul, Brasil & Vilhalva, 2012); Sumaio, 2014 & \\
\hline LS Guarani Kaiowá & Mato Grosso do Sul, Brasil & $\begin{array}{l}\text { Coelho, 2011; Vilhalva, 2012; Lima, } \\
2013\end{array}$ & \\
\hline LS Pataxó & $\begin{array}{l}\text { Aldeia Coroa Vermelha - Bahia, } \\
\text { Brasil }\end{array}$ & Damasceno, 2017 & \\
\hline Cena & Várzea Queimada - Piauí, Brasil & Pereira, 2013 & \\
\hline Acenos & Cruzeiro do Sul - Acre, Brasil & Cerqueira e Teixeira, 2016 & \\
\hline LS da Fortalezinha & Pará - Brasil & Charlize, Formigosa e Cruz, 2016 & \\
\hline LS da Ilha de Marajó & $\begin{array}{l}\text { Ilha de Marajó (Ilha de Soure) - } \\
\text { Pará, Brasil }\end{array}$ & $\begin{array}{l}\text { Martinod, 2013; Formigosa, 2015; } \\
\text { Fusilier, } 2016\end{array}$ & \\
\hline LS de Porto de Galinhas & $\begin{array}{l}\text { Porto de Galinhas - Pernambuco, } \\
\text { Brasil }\end{array}$ & Charlize, Formigosa e Cruz, 2016 & \\
\hline LS de Caiçara & $\begin{array}{l}\text { Sítio Caiçara - Várzea Alegre - } \\
\text { Ceará, Brasil }\end{array}$ & Temoteo, 2008 & \\
\hline $\begin{array}{l}\text { LS de San Juan Quiahije } \\
\text { Chatino }\end{array}$ & México & Hou, 2018 & \\
\hline Sinais de Zinacatan & Chiapas - México & Haviland, 2011, 2013a, & \\
\hline
\end{tabular}




\begin{tabular}{|c|c|c|c|}
\hline & & 2015,2016 & \\
\hline Sinais de Nebaj & Guatemala & Le Guen, 2019 & \\
\hline LS K'iche de Naualá & Guatemala & Fox Tree, 2009 & \\
\hline LS das Ilhas da Baía & $\begin{array}{l}\text { French Harbour/Jonesville - } \\
\text { Honduras }\end{array}$ & Le Guen, 2019 & \\
\hline LS Brunca & Costa Rica & Woodward, 1991 & \\
\hline LS Bribri & Costa Rica & Woodward, 1991 & \\
\hline LS Central Taurus & $\begin{array}{l}\text { Cadeias montanhosas no centro- } \\
\text { sul da Turquia }\end{array}$ & Ergin, 2017; Ergin et al., 2018 & \multirow{5}{*}{ 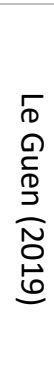 } \\
\hline Sinais Maxakalí & Minas Gerais & Stoianov e Nevins, 2017 & \\
\hline LS de São Tomé e Príncipe & São Tome e Príncipe & Mineiro e Carmo, 2016 & \\
\hline $\begin{array}{l}\text { LS do único surdo da Ilha } \\
\text { Rennel (compartilhada com } \\
\text { os falantes ouvintes) }\end{array}$ & $\begin{array}{l}\text { Ilha de Rennel - Ilhas Salomão, } \\
\text { Polinésia }\end{array}$ & Kuschel, 1973 & \\
\hline $\begin{array}{l}\text { Sinais dos surdos das ilhas } \\
\text { Amami }\end{array}$ & Ilhas Amami - Japão & Osugi, Supalla e Webb, 1999 & \\
\hline
\end{tabular}

Fonte: os autores.

As LSEs atestadas na literatura mostram que o fenômeno da emergência linguística no caso de comunidades surdas isoladas é relativamente ubíquo no Brasil e no mundo, no entanto, devemos ser cautelosos ao classificarmos um sistema de comunicação manual como uma LSE. Esta é a discussão que Almeida-Silva e Sousa (2018) apresentam ao comparar o desempenho em tarefas de produção e compreensão de narrativas em Libras por surdos de comunidades surdas urbanas e isoladas. Os autores atestam que comunidades surdas isoladas se encontram prejudicadas em termos de aquisição de linguagem pela ausência do input sendo ofertado por instituições públicas que viabilizem o acesso cediço à língua de sinais, já que a maioria dos surdos são filhos de pais ouvintes ${ }^{5}$. Os autores chamam atenção para o fato de que a falta de acesso a políticas públicas de estimulação precoce para a aquisição de uma língua não pode ser utilizada como uma explicação para a criação de uma nova variante. As comunidades acima elencadas estão isoladas por várias gerações por questões naturais que decorrem da localização ou modo de vida desta população, o que não pode ser confundindo com os casos de negligência linguística.

Em contextos de LSEs, a maioria dos códigos surge da interação espontânea dos surdos com os gestos utilizados pelos seus familiares ouvintes, ou seja, provavelmente estas LSEs surgem como sinais caseiros, por isso, em todas essas comunidades com LSEs, a língua de sinais é utilizada não só pelos surdos, mas é também compartilhada com os ouvintes. Desse modo, alguém poderia se perguntar se na verdade as LSEs não seriam uma criação dos ouvintes, já que eles são os principais interlocutores dos surdos que compõem as primeiras gerações dessas línguas. Concordamos em parte de que os ouvintes podem sim contribuir com a formação das LSEs e, por isso, essas línguas não se desenvolveriam a partir de um input zero, já que os interlocutores ouvintes forneceriam algum tipo de substrato gestual para que se iniciasse uma comunicação caseira. No entanto, apesar de os ouvintes reconhecidamente contribuírem de algum modo para a formação da LSE, os gestos empreendidos por eles não podem ser equiparados a uma língua de sinais estável, por isso,

\footnotetext{
${ }^{5}$ Ver também Jepson (1991) para uma discussão seminal sobre a temática.
} 
- esforço das crianças surdas de comunidades de LSE é intenso para regularizar a gestualização empregada pelos ouvintes, assim como nos casos de sinalização caseira descritos acima. Somado a esses fatos, na ausência de surdos, nenhuma LSE surgiria, já que os surdos são os únicos responsáveis pela emergência e beneficiados pela manutenção da língua através das gerações. Portanto, a interação com ouvintes, apesar de contribuir para a emergência de uma LSE, nunca poderá ser responsável pela sua organização e fixação.

Os surdos pesquisadores que estavam em nosso grupo nos disseram que ir até a Várzea é uma experiência única para uma pessoa surda, pois é como se fosse uma 'terra de surdos'. Alguns relataram ser a única vez na vida em que dispensaram a ajuda de um tradutor para conversar com pessoas de uma comunidade desconhecida, pois quase todos os habitantes da Várzea 'fazem cena'! A partir de agora, iniciaremos a descrição linguística da LSE da localidade de Várzea Queimada, povoado de Jaicós no Sul do Piauí, a Cena.

\section{A Cena}

A descrição da Cena que efetuamos aqui toma por base a publicação de Pereira (2013), antropólogo que primeiro descreveu a organização social da comunidade apontando para a existência de uma língua de sinais distinta da Libras - Língua Brasileira de Sinais, a língua de sinais utilizada pelos surdos da maioria dos centros urbanos. A tese de Pereira (2013) explora com detalhes todas as formas de trabalho, atividades artísticas e rituais em que os surdos estão envolvidos e como a 'língua dos mudos' desempenha um papel pervasivo em diferentes domínios e rotinas sociais. Apesar de o autor exemplificar em seu texto uma gama de sinais que compõem o léxico da Cena, foge de seus objetivos imediatos fazer uma análise do funcionamento linguístico da língua. Além da tese, também utilizamos o filme Jogos Dirigidos (2019), de Jonathas de Andrade, sobre a LS da Várzea, em que o diretor explora a contação espontânea de diversas narrativas pelos surdos.

\section{O primeiro contato - questões metodológicas}

Grupos de pesquisadores de diferentes universidades do Brasil e do exterior 6 interessados em explicitar o funcionamento linguístico, as questões educacionais envolvendo a Cena e a preservação da LSE realizaram duas viagens com duração média de uma semana cada, 5 a 7 dias, para efetuar coletas de dados, entrevistas e filmagens da Cena em uso. As excursões foram sempre formadas por linguistas, educadores e professores de LSs, surdos e ouvintes, todos com reconhecida expertise em seus campos de atuação. Nenhuma viagem para a comunidade foi realizada sem a presença de surdos pesquisadores. A primeira viagem até a comunidade coordenada pelo nosso grupo se deu em fevereiro de 2017, e a segunda, em dezembro de 2019. Esse intervalo de tempo entre as coletas é importante do ponto de vista metodológico e linguístico, pois contribui para verificar se as

\footnotetext{
6 Universidade Federal do Delta do Parnaíba, Universidade Federal do Rio de Janeiro, University College London, Universidade Federal de Santa Catarina e Universidade Estadual do Ceará.
} 
observações feitas por ocasião da primeira visita são mantidas ou refutadas na segunda.

Nossa tarefa, então, no primeiro contato com a comunidade era aprender os sinais locais, e progressivamente, substituir as formas gestuais que utilizávamos para nos comunicar com os surdos pela Cena local. Nessa tarefa, os pesquisadores surdos têm um papel protagonista, já que a condição auditiva dos pesquisadores ouvintes nos desaproxima dos indivíduos que fazem uso constante de uma LS.

As primeiras coletas dos sinais da Cena foram feitas com os surdos da localidade utilizando estímulos não-verbais impressos que continham categorias lexicais básicas como nomes, verbos e adjetivos, os mesmos utilizados para aquisição de L1 de crianças surdas ${ }^{7}$, e utilizando lista de palavras para os ouvintes sinalizadores que sabiam a Cena. O objetivo inicial era anotar todos os sinais utilizando o sistema Sign $W_{r i t i n g}{ }^{8}$, seus possíveis significados, e nos dias subsequentes, confrontar diferentes sinalizadores sobre o possível significado dos sinais, como uma forma de atestar a estabilidade e o nível de convencionalidade do léxico na comunidade.

Além disso, várias filmagens de conversações espontâneas foram realizadas com objetivo de coletar dados naturalísticos. Toda a coleta foi feita com o consentimento prévio dos falantes, que eram explicados em Cena pelos seus parentes mais próximos (ouvintes bilíngues Cena-português) sobre os objetivos de nossa visita e de como os dados (imagens) poderiam ser utilizados no futuro exclusivamente para a pesquisa científica ${ }^{9}$. Como se trata de uma comunidade geograficamente pequena, nenhuma visita é feita, quaisquer que sejam os objetivos, sem autorização/contato prévio com representantes da comunidade ${ }^{10}$. Os dados que utilizamos para fins deste trabalho são excertos das gravações realizadas com os surdos, os parentes próximos aos surdos e os filhos de surdos, que são falantes nativos bilíngues de Cena. Por isso, nas imagens a seguir, o leitor verá a imagem de algumas crianças. Não utilizaremos, neste artigo, nenhum dado produzido a partir de contação de histórias, por exemplo, mas somente recortes de sinalizações espontâneas. Coletas de dados a partir de elicitação foram realizadas, mas estes dados não aparecem nesta análise.

\footnotetext{
${ }^{7}$ Agradecemos ao CAS - Teresina - em nome de Rachel Andrade e Elisabeth Sousa pela cessão dos materiais que possibilitaram nossa pesquisa de campo.

${ }^{8}$ Sistema de escrita de LS proposto por Valerie Sutton (1995). Ao invés do uso de glosas feitas com base nas LOs, o sistema usa grafemas com base em formas geométricas que, por convenção, designam partes do corpo e movimentos feitos pelo sinalizador. O sistema não é utilizado de forma massiva para a alfabetização de surdos e tem significativa utilidade nas pesquisas com fonologia das LSs.

${ }^{9}$ Em 2017 a pesquisa estava encaixada dentro do Projeto intitulado 'Avaliação de comunidades surdas urbanas e isoladas, cadastrado na PRPPG da Universidade Federal do Piauí desde 2013 com o número CRMV $003 / 2013$. Atualmente a pesquisa consta com a autorização do comitê de ética nacional com o parecer consubstanciado de número 3.853.356. As imagens dos sinalizadores de Cena contidas neste texto estão sendo publicadas com o seu devido consentimento. Inclusive, os falantes da língua estão sendo tratados por seus próprios nomes.

${ }^{10}$ Agradecemos a Dona Silvana (mãe de surdas), Marina (filha e irmã de surdos) e Marcilene (tia de surdos) por serem nossas principais interlocutoras/falantes de Cena.
} 


\section{Padrões urbanísticos $x$ linguísticos}

A Várzea Queimada está localizada geograficamente dentro de um vale e cercada de uma cadeia de morros, o que por muito tempo os manteve afastados de outras localidades. O povoado fica a $398 \mathrm{~km}$ da capital do estado do Piauí - Teresina, e a $27 \mathrm{~km}$ da cidade mais próxima, o município de Jaicós, que administra o povoado da Várzea. Na época do surgimento da Cena, década de 50-60, não havia estrada que ligasse os $7 \mathrm{~km}$ que separam a principal rodovia (BR 407) do povoado, o que fez com que a comunidade ficasse literalmente isolada por muitos anos e isso tem efeitos claros na fixação dos sinais da Cena. Atualmente, o povoado já dispõe de uma estrada de asfalto que chega até a comunidade, mas a Várzea não possui sistema de esgoto nem água encanada, embora disponham de energia elétrica e sinal de internet.

$\mathrm{Na}$ figura 1, organizamos um mapa de acordo com a frequência que os vizinhos surdos estão em contato. O triângulo vermelho indica a rua e as proximidades em que circulam os surdos que moram perto da praça central da comunidade, que por sua vez se encontram $1,5 \mathrm{~km}$ distantes dos surdos que vivem no círculo amarelo. Nesta região do círculo amarelo, vivem os surdos mais velhos que deram origem à Cena e os surdos de gerações mais novas. Por fim, o retângulo verde no canto direito da figura representa a localidade dos três surdos que vivem mais afastados do centro da Várzea, nas Porteiras. Da rua principal (triângulo vermelho) até as porteiras é um trajeto a pé de $3,45 \mathrm{~km}$ de altos e baixos em estrada de terra, ou seja, não é sempre que os surdos das Porteiras estão em contato com os surdos da rua principal ou da rua do meio (círculo amarelo).

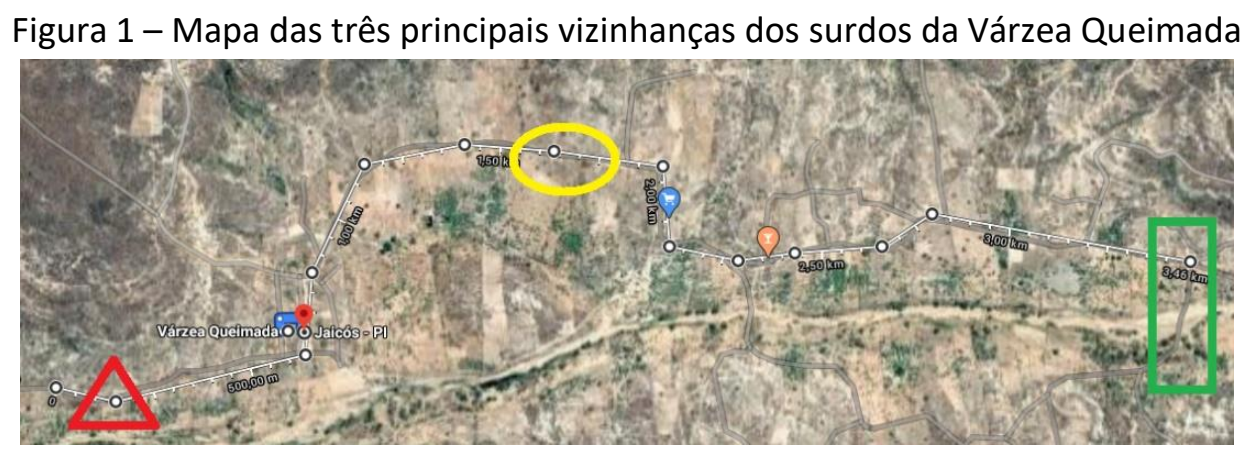

Fonte: Os autores, a partir do Google Maps.

Como resultado dessa distância entre os núcleos de vizinhos surdos, percebemos que alguns sinais possuem variantes decorrentes de possíveis familioletos (SANDLER et al., 2011) e que ainda não foram sistematizados em investigação (socio)linguística.

Como outras comunidades com LSEs, na Várzea também se observa que os surdos não são a maioria dos usuários da LS, pois a Cena também é utilizada pelos ouvintes, por isso, as LSEs são chamadas de línguas compartilhadas. Essa é uma diferença clara entre surdos de centros urbanos e surdos de comunidades isoladas, pois nessas últimas, como a maioria das pessoas conhecem o sistema de comunicação manual, os surdos não sentem os efeitos da estratificação (diglossia) relativos à língua majoritária, o português brasileiro. 


\section{Léxico e gramática}

Nas duas visitas que fizemos até a comunidade coletamos um número grande de sinais que compõem o léxico da Cena. Em momento anterior a nossa pesquisa, Pereira (2013) havia registrado uma média de 85 sinais da língua, considerando um vocabulário dedicado a termos religiosos, sinais de atividades laborais e sinais de parentesco. Em nossa primeira visita em 2017 foram coletados 273 sinais que abrangiam desde nomes relacionados as atividades diárias, mas também um léxico que incluía formas verbais, advérbios e adjetivos. Na segunda visita em 2019, essa lista foi ampliada para algo em torno de 330 sinais, incluindo uma gama de categorias gramaticais que serão publicadas posteriormente em forma de um dicionário.

O léxico da Cena, assim como de outras LSs pode ser analisado considerando duas características: a abrangência e a estabilidade do léxico. A exemplo de outras comunidades isoladas, como são as comunidades indígenas, geralmente o léxico e as narrativas recobrem conceitos ligados as experiências do entorno dos falantes. Por isso, não seria correto comparar o tamanho nem a abrangência de conteúdo do léxico da Cena com a Libras, para a qual o último registro lexicográfico mostra que a língua possui mais de 10.000 sinais lexicalizados (CAPOVILLA et al., 2017).

Em Cena, por exemplo, não se atesta um item dedicado para um conceito como 'estrangeiro', no entanto, isso não impede que ocorra em nossos dados situações nas quais os surdos estejam conversando sobre a noção de estrangeirismo, daremos um exemplo sobre isto mais à frente no texto (seção "Nível Sócio-discursivo"). Nesse sentido, no que se refere a abrangência de conteúdo, o léxico da língua se encontra em expansão como em qualquer língua do mundo, e à medida que os surdos extrapolam seus locais de interação e formação, novos sinais vão sendo incorporados ao léxico. Isso mostra que no desenvolvimento das línguas naturais, o léxico acompanha esse processo de extrapolação dos indivíduos para outros níveis de interação, sejam estes ambientes de discussão sobre conceitos concretos ou abstratos ${ }^{11}$.

Uma questão que ocorre junto ao léxico da Cena atualmente, por exemplo, é a inserção lenta e progressiva de alguns sinais da Libras na língua, conhecidos como os 'sinais da Marcilene', a professora de Libras da comunidade e tia de surdos. Alguns moradores da comunidade dizem que alguns surdos depois que começaram a aprender Libras na escola estão modificando a Cena local. Percebemos em nossas visitas que essa entrada de sinais da Libras na Cena é empreendida pelos surdos mais jovens que frequentam a única escola da comunidade e na qual eles dispõem de aulas semanais de Libras. No entanto, mesmo com as aulas de Libras na comunidade, o fato de que os surdos mais velhos não vão à escola e os

\footnotetext{
${ }^{11} \mathrm{O}$ tipo de mapeamento que foi feito nas línguas de sinais Nicaraguense (SENGHAS; KITA; ÖZYÜREK, 2004) e de São Tomé e Príncipe (MINEIRO; CARMO, 2016) observando como os sinais iniciais se desenvolvem em para formar um sistema linguístico não é mais possível na Cena uma vez que não temos dados da sinalização das décadas interiores. Para uma proposta de comparação de variação considerando o 'tempo aparente' com sinalizadores de diferentes faixas etárias, cf. Woodward (1976).
} 
familiares ouvintes não aprendem a Libras faz com que a Cena prossiga vívida e, de certa forma, resistente as alterações/substituições dos sinais antigos. Contudo, como em qualquer comunidade linguística onde há o contato entre línguas, e principalmente duas línguas de sinais, há uma situação propícia para a ocorrência de empréstimos (THOMASON; KAUFMAN, 1988; ADAM, 2012). A preocupação, da comunidade local de que a Cena seja, então, completamente substituída pela Libras é um risco ainda distante, já que a língua não é de uso exclusivo dos surdos. É instrutivo, por exemplo, comparar com o caso da LS da Jamaica, Konchri Sain, caso em que os surdos se desligaram da LSE local e resolveram seguir a LS nacional. No caso de Cena, não sabemos qual será o futuro da língua, por isso, também, a urgência de sua documentação.

\section{Léxico da Cena}

Na Cena local, não há sinais fixos para todos os dias e meses do ano, no entanto, a comunidade desenvolveu uma estratégia para se referir aos meses que não tem um sinal dedicado, eles utilizam o sinal de PARA FRENTE ou PARA TRÁS, como vemos no exemplo em (1). Desse modo, dias da semana e meses do ano podem ser alcançados tomando como referência os meses que possuem itens fixos, como os em (2) em que vemos da esquerda para direita os sinais referentes ao mês de agosto (mês da festa do vaqueiro), mês de setembro (mês dos festejos em que se instala uma roda gigante na cidade vizinha) e dezembro (mês dos presentes, fazendo referência aos presentes recebidos no nascimento do menino Jesus). No caso de alguém se referir ao mês de outubro ou novembro, meses que não possuem um item na língua, a Cena emprega uma estratégia do tipo em (3) e (4).

(1)

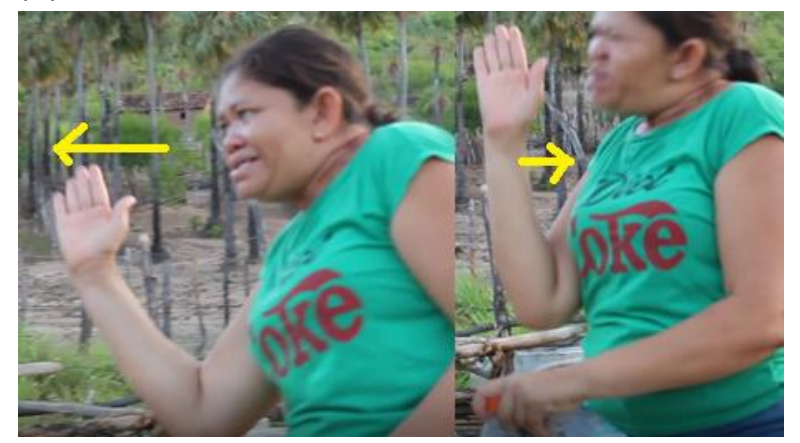

Literalmente: Maura sinaliza 'Para frente' e 'Para trás' ou o 'Sucessor' e o 'Antecessor'

(2)

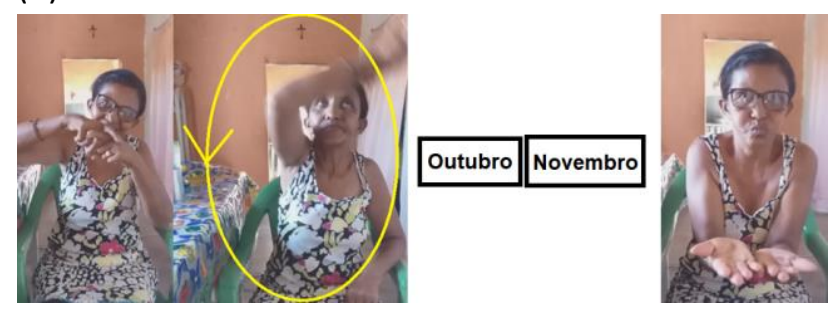

Silvana sinaliza, da esquerda para direita, os três sinais significam respectivamente:

'agosto'/'setembro'/'dezembro' 
(3) SETEMBRO PARA-FRENTE 'outubro'

(4) DEZEMBRO PARA-TRÁS 'novembro'

Os casos podem ainda ser mais complexos do que descrevemos, pois observamos produções em que os usuários de Cena podem efetuar uma gradação (flexão) nos sinais em (1), de modo que eles signifiquem algo próximo a 'muito antes de $x$ ' ou 'muito depois de $x$ '. Essa gradação é efetuada através de, pelo menos, dois mecanismos: distalização da mão e expressão facial de intensidade. Observamos também a estratégia de se contar os meses ou dias como numa equação. No exemplo em (5), o sinal para 'SEGUNDA-FEIRA' é acrescido de uma soma numérica para se chegar ao dia da semana desejado, já que os dias relativos aos dias da semana 'terça, quarta, quinta e sexta' não possuem sinais dedicados na Cena. Esse tipo de contagem dos dias da semana não é incomum em outras línguas como o português brasileiro (ex.: segunda, terça, quarta...) ou em japonês [ex.: ichigatsu (mês-1), nigatsu (mês2)...], e a Cena mostra como essa emergência desses vocábulos pode ter ocorrido.

(5)

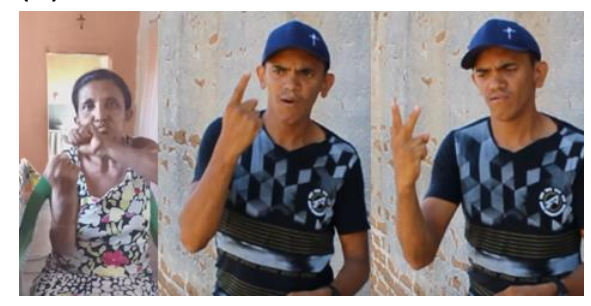

SEGUNDA-FEIRA+1+1 = SEGUNDA-FEIRA+2(DIAS)

'quarta-feira'

A evidência para assumir uma equação aditiva na análise vem do fato de que a adição de dedos nestes casos é sempre feita de um em um, ou seja, não atestamos algo do tipo 'SEGUNDA-FEIRA+2' sendo utilizado para se referir a 'quarta-feira'12. Uma análise mais detalhada da base numeral utilizada pela Cena é necessária para se precisar que tipo de operação está sendo realizada neste caso, já que o sinal para 2 poderia significar ordem, como em 'o segundo dia após a segunda-feira', ou uma operação aditiva como em 'considerando a segunda, você soma mais um, e mais um'.

Para além dos empréstimos, uma outra reação consequente ao contato da Cena com a Libras é o comportamento negativo incorporado pelos próprios surdos da Várzea em relação ao código que eles mesmos desenvolveram. $E$ isso nos faz lembrar as palavras de Saussure (1916 [2008], p. 86-87) quando diz que todo falante está satisfeito com a língua que tem, e por isso, não pode ter comportamentos negativos em relação à única língua que possui, como por exemplo, não querer falá-la. No entanto, os surdos nos reportam de que o ensino de Libras na comunidade muitas vezes foca aspectos não prioritários como, por

\footnotetext{
12 Para entender como LSEs utilizam diferentes operações numéricas para desenvolver sua base numeral remetemos o leitor à análise de Zeshan et al. (2013).
} 
exemplo, asseverar que os sinais da Cena são errados, feios, e a Libras seria a língua correta, ou ainda, reforçar o estigma de que a Cena seria ineficiente para a comunicação já que não dispunha de um léxico extenso como o da Libras, o que já explicamos em parágrafo acima.

Durante a nossa segunda visita à comunidade, desenvolvemos em conjunto com os surdos pesquisadores uma 'Oficina de Libras $x$ Cena' ${ }^{13}$, buscando mostrar para a comunidade local que a língua deles é em muitos aspectos traduzível para a Libras, fazendo inclusive jogos do tipo: Como diríamos isto em Cena? e Como seria em Libras? No decorrer da atividade, percebemos que os surdos da Várzea se comportam tal qual aprendizes de L2, que resistem não somente à refixação de aspectos de sua gramática, mas também têm dificuldade de adquirir o novo léxico que lhes é apresentado. Ou seja, isso evidencia que a Cena atende os requisitos comunicativos da comunidade e provavelmente, qualquer educador ou linguista interessado em aproximar-se da comunidade terá de aprender primeiro a Cena local, porque ela é a língua dos surdos, sejam quais forem os objetivos secundários. Este relato sinaliza para a estabilidade que o léxico desenvolvido pela comunidade tem dentro da Várzea.

Uma outra ocorrência que evidencia a estabilidade do léxico da Cena é a existência de falsos cognatos entre a Cena e a Libras. Ao chegarmos na comunidade, um de nossos pesquisadores surdos, doravante (A), se aproximou de uma pessoa da Várzea (B) e perguntou-Ihe, usando o sinal da Libras para SURDO em (6), se ele era surdo. Usando uma expressão facial típica de perguntas de 'questões de sim-ou-não' com as sobrancelhas levantadas (7), o diálogo entre os dois está glosado em (8).

(6)

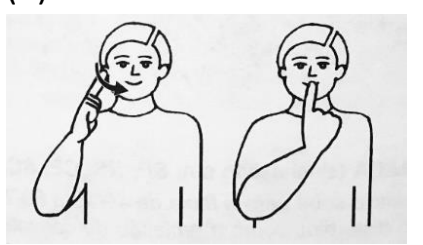

'surdo/a'

Fonte: Capovilla et al. (2017, p. 2643).

(7)

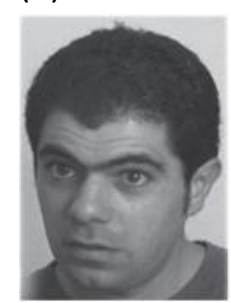

Fonte: Dachkovsky e Sandler (2009, p. 295).

\footnotetext{
${ }^{13}$ Além disso, outras atividades são realizadas durante nossas coletas de dados, tais como exibição de filmes sobre outras LSE no mundo e o planejamento de elaboração de materiais que valorizem a língua local.
} 
(8)

expressão-questão-sim-ou-não ${ }^{14}$

A (surdo-pesquisador): VOCÊ SURDO?

'você é surdo'

B (surdo da Várzea): NÃO

$A$ resposta de $B$ causou inquietação a $A$ logo que descobrimos que $B$ era surdo. Somente depois de começarmos a investigar o léxico da Cena com detalhes, descobrimos que em Cena, o simples toque do indicador na boca e no ouvido, como é o sinal para SURDO em Libras em (6), indica 'ser ouvinte', ou seja, indica que a audição e a fala estão em pleno funcionamento. Quando o surdo B da Várzea, respondendo de acordo com o código local, foi perguntado se escutava e falava, como se observa no diálogo em (8), obviamente, respondeu que não. Daí observamos que o critério utilizado em Cena para identificar alguém como surdo ou ouvinte deve ser feito através das expressões faciais afirmativas (no caso de ser ouvinte) e negativa (no caso de surdo) junto às apontações para a boca e ouvido simultaneamente, ou, como em (9ab) abaixo, Silvana sinaliza uma partícula manual de afirmação ou de negação, que deve ser adicionada para mudar o significado do sinal.

(9)

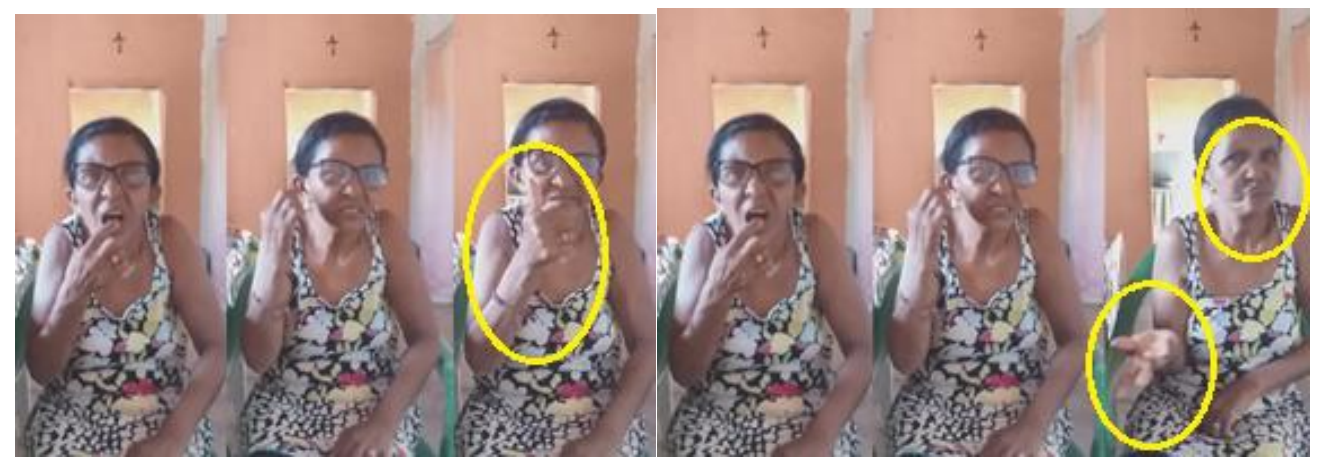

a. 'ouvinte'

b. 'surdo'

Apesar do léxico pequeno, a Cena já apresenta recursos semânticos de aumento de expressividade lexical utilizando os mesmos significantes com diferentes significados, diminuindo assim, a carga de memória dos falantes. Um exemplo são os sinais homônimos em (10), que como em outras línguas, somente são desambiguizados pelo contexto pragmático ou sintático em que são produzidos. Por questões de espaço, neste artigo não poderemos explorar as estratégias sintáticas que ativam uma interpretação ou outra do sinal.

\footnotetext{
${ }^{14}$ A linha sobrescrita nas glosas indica que a expressão facial é realizada simultaneamente ao sinal manual como um suprassegmento.
} 


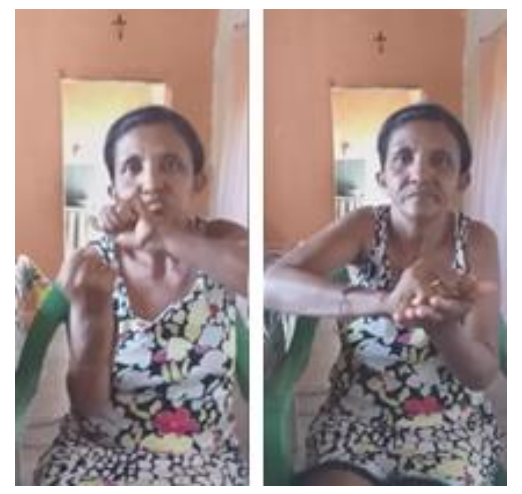

Sinal à esquerda: CARRO/DIRIGIR ou SEGUNDA-FEIRA ${ }^{15}$

Sinal à direita: LAVAR-OBJETOS ou SÁBADO

A Cena não possui sinais para os termos que designam cores básicas na língua, no entanto, possui dois sinais para tons de pele, a saber, NEGRA e BRANCA, ficando assim abaixo da média de outras LSEs que possuem pelo menos três ou quatro sinais para as cores básicas como tem sido reportado nos estudos de De Vos (2011) e Adone et al. (2012). Contudo, a exemplo de outras LSEs, a Cena emprega o sinal de PELE como uma estratégia para se ativar o campo semântico relacionado a cores e, em seguida, apontar para algum objeto que possua a cor desejada, ou seja, a estratégia da apontação não lexical precedida do sinal PELE é a estratégia mais comum para se referir a cores pelos falantes de Cena.

Há um vocabulário robusto na Cena relacionado a animais, comida, festas religiosas e santos, sujeitos à variação nos sinais de acordo com familioletos ou ainda à geração a que pertencem os falantes, por exemplos em (11), os sinais de PEIXE e GALINHA. O sinal mais à direita em (11) é de Ida, uma criança CODA (child of deaf adult - filha de surdos), que usa Cena diariamente com a mãe, tia, e todos os vizinhos, e o mais à esquerda é Francisco, surdo da Várzea.

(11)

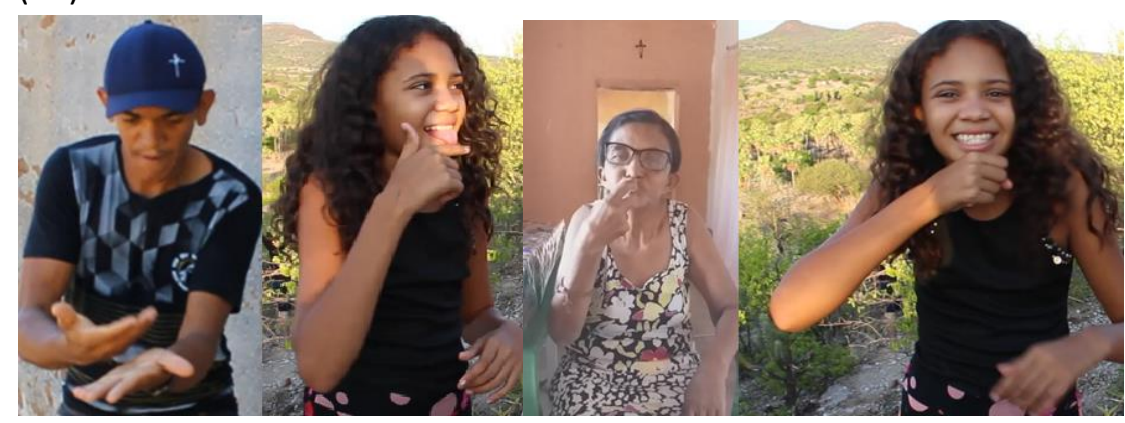

Variantes do sinal 'peixe'

Variantes do sinal 'galinha'

\footnotetext{
${ }^{15}$ Segunda-feira é o dia em que os "carros", que, como explica Pereira (2013), pode designar motos, ônibus ou outros automóveis, levam as pessoas para a cidade de Jaicós e sábado seria o dia em que geralmente se lavaroupas. Martins (2013) denomina esses tipos de ambiguidades como 'determinantes evocativos', pois é possível mapear sua possível origem, mas sincronicamente os contextos que deram origem à relação de ambiguidade lexical não são completamente acessíveis.
} 


\section{Nível fonético-fonológico}

No nível fonético-fonológico, a primeira observação é que a Cena emprega um ritmo mais abrupto e demanda o uso concomitante de mais articuladores do que a Libras. $O$ fato de que a língua explora, para além do léxico existente, recursos pantomímicos, apontações para espaços reais e outros recursos gestuais que gradualmente se lexicalizam, reclama condições articulatórias que exigem um esforço corporal observável. Não somente na prosódia, mas no nível fonológico e sintático são observados, em outras LSEs, comportamentos desse tipo, em que coexistem etapas do desenvolvimento linguístico com altos graus de variação, quer no uso de fonemas ou no emprego de diferentes ordens sintáticas (SANDLER, 2017; ERGIN et al., 2018). Nesses períodos, o comportamento fuzzy das estruturas nos diferentes níveis linguísticos nos dá uma aparente sensação de ausência de hierarquia ou sistematicidade. Sandler (2017, p. 58) postula que "uma língua pode ser completamente funcional antes que uma sistematização da fonologia seja cristalizada" sugerindo que o uso diário do sistema de comunicação, a convencionalização e a automaticidade no uso das formas pode sobrepujar a relação forma-significado e aproximarse um sistema formal.

Não existe um alfabeto manual em Cena, e por isso, nenhum dos sinais coletados possui configurações de mão que espelhem as letras do alfabeto do português ${ }^{16}$. Observamos a existência de sinais muito semelhantes fonologicamente, ou seja, que possuem as mesmas configurações de mão, localização e direção da palma, mas que aparentemente se contrastam com o uso de diferentes expressões faciais, como são os exemplos de Denílson e Silvana em (12) e Francisco em (13) abaixo.

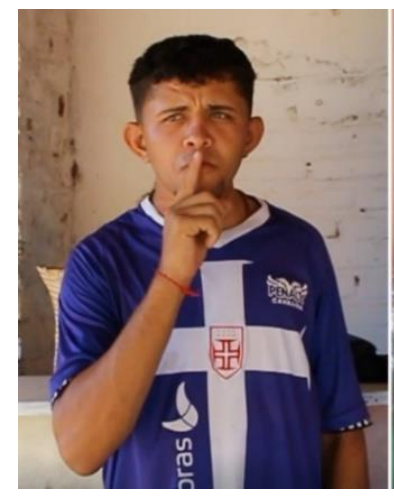

'falar' vs. 'fogo'

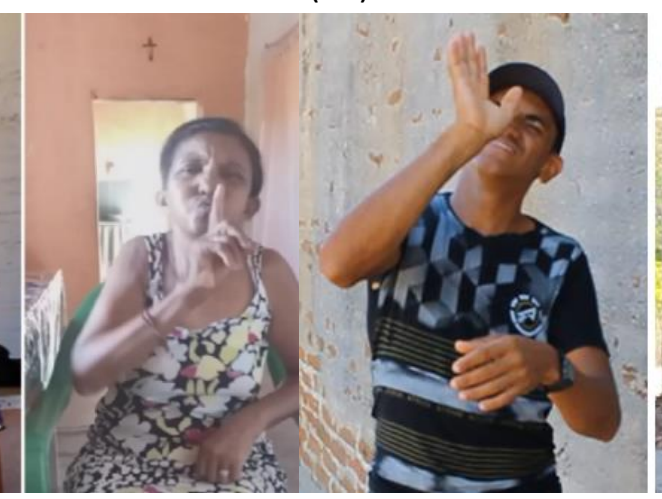

'noite' vs. 'meio-dia'

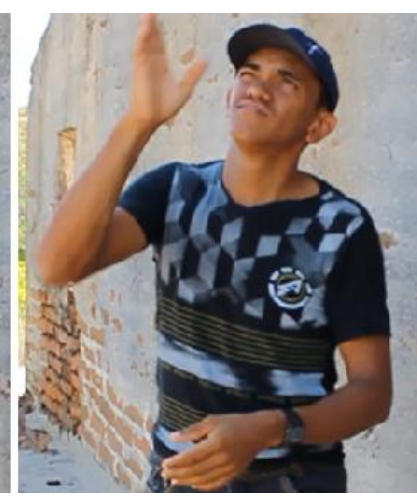

$$
\text { ( }
$$


Em trabalhos futuros, pretendemos investigar o papel de marcação facial para distinguir itens lexicais, a partir dos usos atestados em Libras (TAKAHIRA, 2015). Também ressaltamos a importância de rastrear o uso da mão não dominante, o uso opcional/alofônico do polegar e a variação inter e intra-individual de versões bimanuais de sinais.

\section{Nível morfossintático}

No nível morfológico, a Cena exibe compostos que não são decalques dos compostos encontrados em Libras (XAVIER; NEVES, 2016) ou outras línguas de sinais, do mesmo modo que se atesta em outras LSEs como na Língua de Sinais Al-Sayid Beduína e na Língua de Sinais Central Taurus (ver referências no quadro apresentado na seção "O que são e por que investigar as LSEs?"). Em (14) abaixo, vemos o morfema-base 'FOGO/CALOR' sendo utilizado para o sinal de FOGUEIRA no composto à esquerda na imagem, e um uso composicional do morfema aparece no composto à direita, no sinal de SOL.

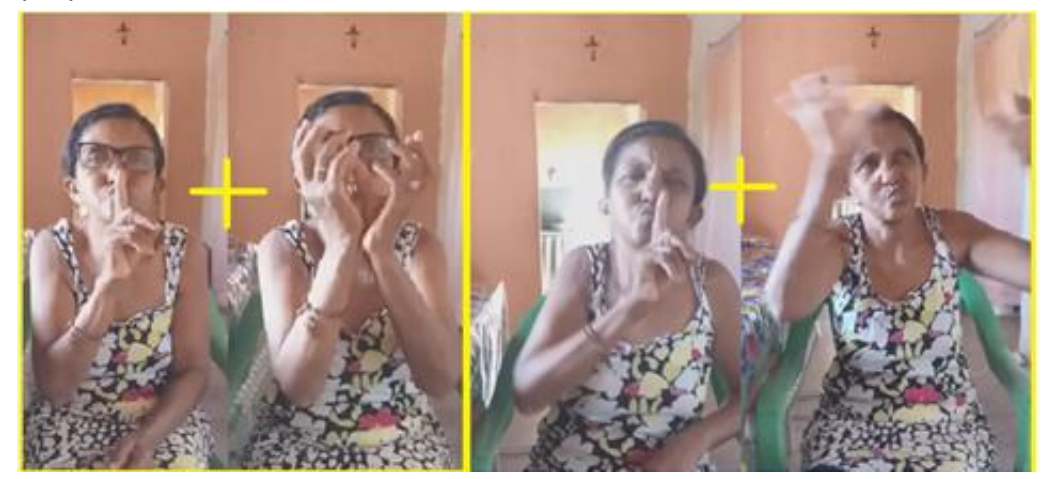

Esq: FOGO/CALOR^CL:OBJ.REDONDO=FOGUEIRA

Dir: FOGO/CALOR^CL:RAIOS-SOLARES= SOL

Muitos sinais utilizam a referência exofórica, ou seja, apontam para a posição real dos referentes no mundo. Assim como na LS de Kata Kolok (DE VOS, 2012), a Cena utiliza pontos de referência absolutos para criar sinais. É o caso, por exemplo, dos sinais para expressar os períodos do dia em (15). A configuração de mão aponta para o local exato do nascer do sol na cidade e vai acompanhando o movimento do sol até o poente. Interessantemente, não importa a posição que o falante esteja em uma conversa, ele sempre vai apontar no sentido do sol nascente ou poente, o que indica uma estratégia convencionalizada, porém, não lexicalizada para se codificar as noções de período do dia. 


\section{(15)}

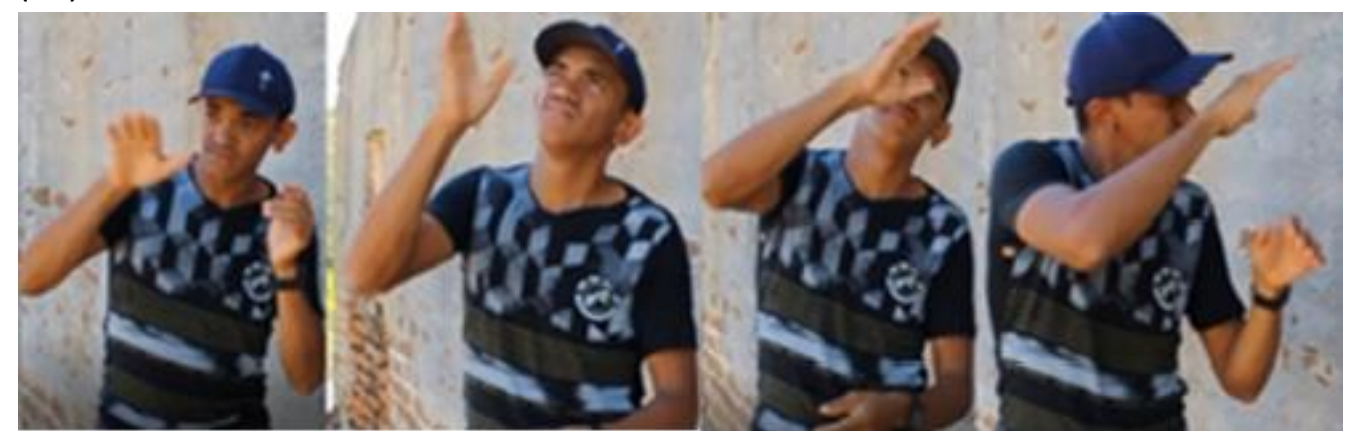

Da esquerda para direita: 'meio da manhã', 'meio-dia', 'meio da tarde' e 'pôr-do-sol'17

Ainda no nível morfológico, na Cena já se atestam gradações típicas de modificações adverbiais realizadas por articuladores não manuais como a face. Assim como nota Xavier (2017) para a Libras, o uso de "sobrancelhas franzidas, bochechas infladas, tronco inclinado, e mudanças no número de mãos e duração do sinal" são recursos miméticos metaforicamente vinculados a noção de intensidade. Por isso, no exemplo em (16), o sinal manual MANHÃ, acrescido da expressão facial intensificada e da curvatura do tronco, aumentam o significado do sinal para 'bem de manhã' ou 'muito cedo'.

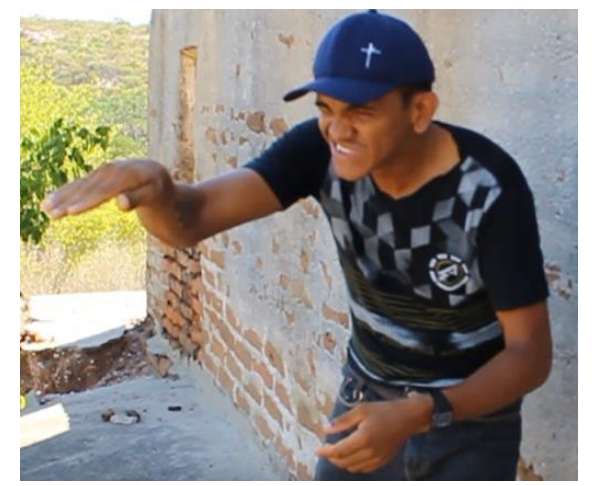

expressão-corporal-intensidade

MANHÃ

'muito cedo'

$\mathrm{Na}$ interface da morfologia com a sintaxe, relativo ao uso do espaço para o estabelecimento do sistema pronominal, identificamos que os usuários da Cena usam a mesma estratégia que os falantes de Libras, fazendo o uso da apontação ego-alinhada ao peito do sinalizador para identificar a primeira pessoa, e as apontações ego-opostas para a segunda e terceira pessoa do discurso. No entanto, não foi possível identificar o uso do mesmo tipo de apontações (pronominais) para falar sobre referentes ausentes. Nesses casos, quando querem referir-se a pessoas que não estão presentes no contexto de fala,

\footnotetext{
${ }^{17}$ Como o Piauí fica próximo à linha do Equador, é possível acompanhar claramente o movimento do sol sobre a comunidade. Por hipótese, comunidades de LSEs mais próximas aos polos terrestres desenvolveriam outro tipo de estratégia para este mesmo contexto.
} 
apontam para a localização real mais provável dessa pessoa, como por exemplo, a direção da casa, ou a provável distância que estamos do referente ausente, mas não observamos o uso dos pronomes de segunda e terceira pessoa para referentes ausentes sem que a apontação esteja direcionada para a provável localização real do referente. Essa é uma possível diferença tipológica entre LSEs e línguas de sinais estáveis e pode lançar luz sobre como os traços pronominais surgem e se desenvolvem nas línguas naturais.

\section{Nível sintático}

Observamos que a Cena, assim como outras LSEs, apresenta grande variação da ordem da sentença, e uma investigação mais detalhada é necessária para que se possa compreender mais sobre os limites prosódicos entre constituintes na língua. A posse em Cena é expressa por justaposição, e identificamos a ausência de verbos existenciais do tipo ter ou haver. A negação em Cena pode ser feita com a face, como em várias outras LSs, com o uso do headshake (balanço da cabeça para os lados) e do horseshoe mouth (boca de ferradura $(2)$, no entanto, também observamos a existência de itens manuais negativos na língua.

A Cena também emprega expressões-faciais e itens manuais para codificar sentenças interrogativas como vemos no exemplo em (17).

\section{(17)}

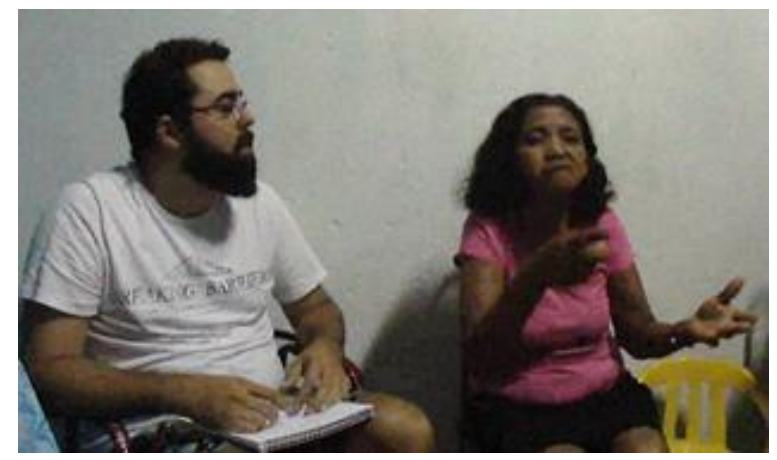

expressão-facial-interrogativa

PALMAS-PARA-CIMA: pode significar qualquer elemento QU.

O único item QU identificado na língua é o sinal de QUANTA/O(s), no exemplo em (18), que geralmente é sinalizado em posição final na sentença. 
(18)

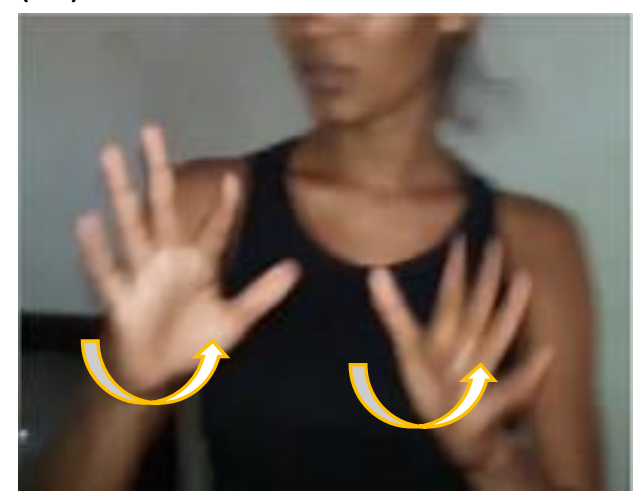

QUANTA/O(s): As duas mãos com as palmas abertas rotam simultaneamente para frente e para trás.

Em trabalhos futuros, pretendemos elicitar estruturas sintáticas para conjunção e disjunção, para verificar se há ambiguidade dos marcadores lógicos (QUER; STEINBACH, 2015) e como esse tipo de ambiguidade é resolvida.

\section{Nível sócio-discursivo}

Diferentemente de línguas de sinais nacionais, na Cena, saudações e estratégias de polidez, como 'bom dia', 'com licença' ou 'de nada' não são observadas. No entanto, os surdos nos relatam de casos de 'provocações' individualizadas que funcionam como 'saudações' dentro da comunidade. Então, por exemplo, um surdo nos relatou que sempre que vê o padre da cidade, brinca/o saúda fazendo o sinal de FACA, como uma ameaça de que cortaria a genitália do padre, já que ele fez o voto de castidade.

É comum o uso de recursos metafóricos para expressar conceitos não lexicalizados na língua, e isso evidencia a integridade do sistema cognitivo dos surdos usuários da Cena. Nas produções, atestamos o uso de expressões metafóricas para codificar conceitos específicos como, por exemplo: i) para explicar que uma das integrantes da equipe de pesquisadores era estrangeira, os usuários de Cena empregam expressões como: ELA LÁ PESSOAS FALAR NÃO-ENTENDER que significa 'ela vem de onde as pessoas falam línguas que não entendemos', ou ainda, AQUI 3H TARDE LÁ NOITE, para dizer 'ela vem de um lugar com diferença de fusos horários'; ii) para dizer que o benefício de um deles havia sido 'cortado' ou 'descontinuado', o sinalizador usa sinais como BENEFÍCIO CORTAR-COM-TESOURA, LÁ POLICIAL FILA RETA RETIRAR-DA-FILA POLITICO ROUBAR', que se refere à seguinte tradução 'meu benefício foi cortado, o guarda lá da agência, sempre que ele me tira da fila, significa que vou perder o benefício, estes políticos são ladrões!' e iii) para designar distâncias ou cidades que não possuem sinais em Cena, eles usam expressões de referência aproximada como DEMORAR CARRO, DEMORAR AVIÃO, RIO DEPOIS, LÁ MAR, para dizer que uma cidade ou localidade 'se leva tempo para chegar de carro', 'de avião', 'fica depois do rio' ou 'próximo ao mar'.

Ou seja, essas expressões são recursos pragmáticos-discursivos de interface entre o sistema linguístico e o sistema cognitivo através da noção de cognição corporificada 
(LAKOFF; JOHNSON, 2008; LAKOFF, 2008). Portanto, apesar do tamanho, abrangência e nível de estabilidade do léxico da Cena, vimos nesta descrição inicial que os usuários de Cena dispõem de todos os recursos estruturais básicos de uma língua natural, aliados à plena capacidade expressiva do sistema cognitivo de seus usuários.

\section{Conclusões}

A descrição que efetuamos da Cena neste artigo é somente preliminar e aponta para uma agenda de investigações que se abrem não somente para a língua Cena, mas para a temática das línguas de sinais emergentes. A análise revela que o contato social denso e o isolamento geográfico da comunidade de outras línguas de sinais funcionaram como os ingredientes que a fizeram emergir e também garantiram a manutenção e estabilidade do léxico da Cena ao longo dos anos.

Mostramos que a Cena, a exemplo de outras línguas estáveis, dispõe de recursos linguísticos estruturais que são regularizados por uma capacidade inata dos usuários de desenvolverem, por exemplo, o contraste fonológico, a emergência de um sistema de grau e o processo de composição de palavras, ou ainda, o emprego de recursos semânticos de expressividade, além de outros recursos de ordem discursivo-pragmáticas. Portanto, a Cena, assim como outras línguas de sinais emergentes, contribui com a discussão sobre como as línguas humanas podem ter surgido e quais teriam sido os possíveis passos da emergência linguística.

Assim como em outras línguas, a organização sociolinguística da comunidade tem efeitos claros pelo menos para a variação identificada no nível lexical e abre espaço para discussões relevantes no âmbito educacional e político considerando o contexto de línguas minoritárias.

\section{Agradecimentos}

Aos colegas Mário André Coelho da Silva, Marília Lott, Maria Luisa Freitas, Diane Stoianov, André Xavier, Glauber Romling da Silva, Gustavo Godoy e Livia Camargo Souza pelos comentários prévios feitos neste texto. Aos colegas que compuseram a primeira excursão em 2017: Anderson Almeida da Silva, Natália de Almeida Simeão, Diná Souza da Silva, Antônio Nelson Teixeira Moreno, Kelly Samara Pereira Lemos, João Cunha e Silva Neto, e os da segunda excursão em 2019: Anderson Almeida da Silva, Andrew Ira Nevins, lago Pedro Pires, Carlos Douglas Carvalho de Macedo, Diane Stoianov, Telma Franco, Bruna Rodrigues da Silva, Nadia Fernanda Martins de Araujo.

\section{Referências}

ADAM, Robert. Language contact and borrowing. In: PFAU, Roland; STEINBACH, Markus; WOLL, Bencie. Sign language: An International Handbook. Berlim/Boston: De Gruyter Mouton, 2012. p. 841-861. https://doi.org/10.1515/9783110261325 
ADONE, Dany et al. Colour signs in two indigenous sign languages. In: ZESHAN, Ulrike; DE VOS, Connie. Sign languages in village communities: Anthropological and linguistic insights. Boston/Berlin e Nijmegen: De Gruyter Mouton and Ishara Press, 2012. p. 53-86. https://doi.org/10.1515/9781614511496.53

ALMEIDA-SILVA, Anderson; SOUSA, Roger S. Avaliação da capacidade expressiva e de compreensão da Libras: um estudo comparativo entre a aquisição de linguagem em comunidades surdas urbanas e desligadas. In: STUMPF, Marianne R.; DE QUADROS, Ronice M. Estudos da Língua de Sinais, vol. 4. Florianópolis: Insular, 2018. p. 37-60.

ARONOFF, Mark et al. The roots of linguistic organization in a new language. In: ARBIB, Michael A.; BICKERTON, Derek The Emergence of Protolanguage. Holophrasis vs. Compositionality. Amsterdam: John Benjamins Publishing Company, 2010. p. 133-152. https://doi.org/10.1075/bct.24.09aro

BARAKAT, Robert A. The Cistercian sign language: a study in non-verbal communication. Kalamazoo, Mich.: Cistercian Publications, 1975. https://doi.org/10.1353/sls.1975.0007

BRAITHWAITE, Ben. Sign language endangerment and linguistic diversity. Language, v. 95, n. 1, p. e161-e187, 2019. https://doi.org/10.1353/lan.2019.0025

CAPOVILLA, Fernando C. et al. Dicionário da Língua de Sinais do Brasil. A Libras em suas Mãos. 3 Volumes. São Paulo: Edusp, 2017.

CHOMSKY, Noam. Aspects of the Theory of Syntax. Cambridge: MIT Press, 1965. https://doi.org/10.21236/AD0616323

COUTO, Hildo Honório do. Introdução ao Estudo das Línguas Crioulas e Pidgins. Brasília: Editora Universidade de Brasília, 1996.

DACHKOVSKY, Svetlana; SANDLER, Wendy. Visual intonation in the prosody of a sign language. Language and speech, v. 52, n. 2-3, p. 287-314, 2009. https://doi.org/10.1177/0023830909103175

DE VOS, Connie. Kata Kolok color terms and the emergence of lexical signs in rural signing communities. The Senses and Society, v. 6, n. 1, p. 68-76, 2011.

https://doi.org/10.2752/174589311X12893982233795

DE VOS, Connie. Sign-spatiality in Kata Kolok: How a village sign language of Bali inscribes its signing space. 2012. Tese de Doutorado. Radboud University Nijmegen, Nijmegen, 2012.

DE VOS, Connie; PFAU, Roland. Sign language typology: the contribution of rural sign languages. Annu. Rev. Linguist., v. 1, n. 1, p. 265-288, 2015.

https://doi.org/10.1146/annurev-linguist-030514-124958

ERGIN, Rabia. Central Taurus Sign Language: A Unique Vantage Point into Language Emergence. 2017. Tese de Doutorado. Tufts University, Medford/Somerville, 2017. https://doi.org/10.1353/sls.2018.0018

ERGIN, Rabia et al. The Development of Argument Structure in Central Taurus Sign Language. Sign Language Studies, v. 18, n. 4, p. 612-639, 2018.

FROMKIN, Victoria et al. The development of language in Genie: A case of language acquisition beyond the "critical period". Brain and language, v. 1, n. 1, p. 81-107, 1974. https://doi.org/10.1016/0093-934X(74)90027-3 
GODOY, Gustavo. Os Ka'apor: seus gestos e sinais. Tese de doutorado. Programa de Pósgraduação em Antropologia Social - Museu Nacional, Universidade Federal do Rio de Janeiro. 2020.

GOLDIN-MEADOW, Susan; MYLANDER, Carolyn. Beyond the input given: The child's role in the acquisition of language. Language, v. 66, n. 2, p. 323-355, 1990.

https://doi.org/10.2307/414890

GROCE, Nora Ellen. Everyone here spoke sign language. Harvard: Harvard University Press, 1985.

HINDLEY, Philip Colin. Nominal and imperative iconic gestures used by the Khoisan of North West Botswana to coordinate hunting. African Study Monographs, v. 35, n. 3\&4, p. 149181, 2014.

HOU, Lynn. Iconic Patterns in San Juan Quiahije Chatino Sign Language. Sign Language Studies, v. 18, n. 4, p. 570-611, 2018. https://doi.org/10.1353/sls.2018.0017

JEPSON, Jill. Urban and rural sign language in India. Language in Society, v. 20, n. 1, p. 37-57, 1991. https://doi.org/10.1017/S0047404500016067

JOGOS DIRIGIDOS [filme]. Direção de Jonathas de Andrade. Produção: Vanessa Barbosa. $57^{\prime \prime}, 2019$.

JOHNSON, Jacqueline S.; NEWPORT, Elissa L. Critical period effects in second language learning: The influence of maturational state on the acquisition of English as a second language. Cognitive psychology, v. 21, n. 1, p. 60-99, 1989. https://doi.org/10.1016/0010$\underline{\text { 0285(89)90003-0 }}$

KENDON, Adam. Knowledge of sign language in an Australian Aboriginal community. Journal of Anthropological Research, v. 40, n. 4, p. 556-576, 1984.

https://doi.org/10.1086/jar.40.4.3629797

KUSCHEL, Rolf. The Silent Inventor: The Creation of a Sign Language by the Only Deaf-Mute on a Polynesian Island. Sign Language Studies, v. 3, n. 1, p. 1-27, 1973.

https://doi.org/10.1353/sls.1973.0019

LAKOFF, George. Women, fire, and dangerous things: What categories reveal about the mind. Chicago: University of Chicago Press, 2008.

LAKOFF, George; JOHNSON, Mark. Metaphors we live by. Chicago: University of Chicago Press, 2008.

LE GUEN, Olivier. Emerging Sign Languages of Mesoamerica. Sign Language Studies, v. 19, n. 3, p. 375-409, 2019. https://doi.org/10.1353/sls.2019.0002

LENNEBERG, Eric H. The biological foundations of language. Hospital Practice, v. 2, n. 12, p. 59-67, 1967. https://doi.org/10.1080/21548331.1967.11707799

MARTINS, Tânia Aparecida. Um estudo descritivo sobre as manifestações de ambiguidade lexical em LIBRAS. 2013. 158 f. Dissertação de Mestrado - Mestrado em Letras - Centro de Educação, Comunicação e Artes. Universidade Estadual do Oeste do Paraná. Campus de Cascavel, 2013.

MEIR, Irit et al. Emerging sign languages. In: MARSCHARK, Marc; SPENCER, Patricia Elizabeth. Oxford handbook of deaf studies, language, and education. Oxford: Oxford University 
Press, 2010. p. 267-280.

MEISSNER, Martin; PHILPOTT, Stuart B.; PHILPOTT, Diana. The sign language of sawmill workers in British Columbia. Sign Language Studies, v. 9, n. 1, p. 291-308, 1975. https://doi.org/10.1353/sls.1975.0010

MINEIRO, Ana; CARMO, Patrícia. Língua Gestual de São Tomé e Príncipe: retrato dos primeiros gestos. Linguística: revista de estudos linguísticos da Universidade do Porto, v. 11, p. 161-182, 2017.

MORGAN, Gary. Critical period in language development. Encyclopedia of language development. Thousand Oaks, CA: SAGE Publications, Inc, 2014. p. 115-118.

OSUGI, Yutaka; SUPALLA, Ted; WEBB, Rebecca. The use of word elicitation to identify distinctive gestural systems on Amami Island. Sign language \& linguistics, v. 2, n. 1, p. 87112, 1999. https://doi.org/10.1075/sll.2.1.12osu

PEREIRA, Éverton Luís. Fazendo cena na cidade dos mudos: surdez, práticas sociais e uso da língua em uma localidade no sertão do Piauí. 380 f. 2013. Tese de Doutorado, Universidade Federal de Santa Catarina, Centro de Filosofia e Ciências Humanas, Programa de PósGraduação em Antropologia Social, Florianópolis, 2013.

PFAU, Roland; STEINBACH, Markus; WOLL, Bencie (Ed.). Sign language: An international handbook. Walter de Gruyter, 2012. https://doi.org/10.1515/9783110261325

QUER, Josep; STEINBACH, Markus. Ambiguities in sign languages. The Linguistic Review, v. 32, n. 1, p. 143-165, 2015. https://doi.org/10.1515/t|r-2014-0018

REED, Lauren W. Sign Languages of Western Highlands, Papua New Guinea, and their Challenges for Sign Language Typology. Master of General and Applied Linguistics. The Australian National University, Canberra, 2019.

SANDLER, Wendy et al. The emergence of grammar: Systematic structure in a new language. Proceedings of the National Academy of Sciences, v. 102, n. 7, p. 2661-2665, 2005. https://doi.org/10.1073/pnas.0405448102

SANDLER, Wendy; ARONOFF, Mark; MEIR, Irit; PADDEN, Carol. The gradual emergence of phonological form in a new sign language. Natural Language \& Linguistic Theory, v. 29, n. 2, p. 503-543, 2011. https://doi.org/10.1007/s11049-011-9128-2

SANDLER, Wendy et al. Language emergence: Al-Sayyid Bedouin sign language. In: SIDNELL, Jack; KOCKELMAN, Paul; ENFIELD, N. J. Cambridge Handbook of Linguistic Anthropology. Cambridge University Press, 2014. p. 250-284.

https://doi.org/10.1017/CBO9781139342872.012

SANDLER, Wendy. The challenge of sign language phonology. Annual review of Linguistics, v. 3, p. 43-63, 2017. https://doi.org/10.1146/annurev-linguistics-011516-034122

SAUSSURE, Ferdinand. Curso de linguística geral. Editora Cultrix, [1916] 2008.

SENGHAS, Ann; KITA, Sotaro; ÖZYÜREK, Asli. Children creating core properties of language: Evidence from an emerging sign language in Nicaragua. Science, v. 305, n. 5691, p. 17791782, 2004. https://doi.org/10.1126/science.1100199

SILVA, Diná Souza; DE QUADROS, Ronice Muller. Línguas de sinais de comunidades isoladas encontradas no Brasil/Sign languages of isolated communities found in Brazil. Brazilian 
Journal of Development, v. 5, n. 10, p. 22111-22127, 2019.

https://doi.org/10.34117/bjdv5n10-342

SINGLETON, Jenny L.; NEWPORT, Elissa L. When learners surpass their models: The acquisition of American Sign Language from inconsistent input. Cognitive psychology, v. 49, n. 4, p. 370-407, 2004. https://doi.org/10.1016/i.cogpsych.2004.05.001

STOIANOV, Diane; NEVINS, Andrew. The phonology of handshape distribution in Maxakalí sign. In: LINDSEY, Geoff; NEVINS, Andrew. Sonic signatures: Studies dedicated to John Harris. Amsterdam/Philadelphia: John Benjamins Publishing Company, 2017. p. 231-262. https://doi.org/10.1075/Ifab.14.c14

SUTTON, Valerie. Lessons in sign writing. SignWriting. La Jolla: Center for Sutton Movement Writing, 1995.

TAKAHIRA, Aline Garcia Rodero. Compostos na língua de sinais brasileira. 2015. Tese de Doutorado. Faculdade de Filosofia, Letras e Ciências, Programa de Pós-Graduação em Semiótica e Lingüística Geral, Universidade de São Paulo, 2015.

THOMASON, Sarah Grey; KAUFMAN, Terrence T. Language Contact, Creolization and Genetic Linguistics. Berkeley/Los Angeles/Oxford: University of California Press, 1988.

TOMKINS, William. Indian Sign Language. Courier Corporation, [1931] 1969.

XAVIER, André Nogueira; NEVES, Sylvia Lia Grespan. Descrição de aspectos morfológicos da Libras. Revista Sinalizar, v. 1, n. 2, p. 130-151, 2016. https://doi.org/10.5216/rs.v1i2.43933

XAVIER, André Nogueira. A expressão de intensidade em Libras. Intercâmbio, v. XXXVI, p. 125, 2017.

WOODWARD, James C. Signs of change: historical variation in American Sign Language. Sign Language Studies, n. 10, p. 81-94, 1976. https://doi.org/10.1353/sls.1976.0003

ZESHAN, Ulrike. Roots, leaves and branches. The typology of sign languages. Sign Languages: spinning and unraveling the past, present and future. TISLR9, forty five papers and three posters from the 9th. Theoretical Issues in Sign Language Research Conference. Petrópolis, Editora Arara Azul, 2006. p. 671-695.

ZESHAN, Ulrike et al. Cardinal numerals in rural sign languages: Approaching cross-modal typology. Linguistic Typology, v. 17, n. 3, p. 357-396, 2013. https://doi.org/10.1515/lity$\underline{2013-0019}$

Recebido em: 20/04/2020.

Aceito em: 27/08/2020. 